\title{
A Novel Design of Interval Type-2 Neuro-Fuzzy Controller for Flexible Structure
}

\author{
Mustafa TINKIR*, Mete KALYONCU**, Haşmet Çağrı SEZGEN*** \\ *Necmettin Erbakan University, Department of Mechanical Engineering, Meram, Konya, 42090, Turkey,E-mail: mtin- \\ kir@erbakan.edu.tr \\ **Konya Technical University, Department of Mechanical Engineering, Selçuklu, Konya, 42250, Turkey, \\ E-mail: mkalyoncu@ktun.edu.tr \\ ***Karatay University, Vocational School of Commerce and Industry, Karatay, Konya, 42020, Turkey, \\ E-mail: hasmet.sezgen@karatay.edu.tr
}

crossref http://dx.doi.org/10.5755/j02.mech.25134

\section{Introduction}

Vibration controls against disturbances such as earthquake accelerations are important in the design of the flexible structures. Generally, the methods for vibration control are categorized as active and passive vibration control approaches [1-3]. Although application of the passive control methods is easy and economical, the reported works in the literature indicate that the active control methods are more effective in terms of decreasing the vibration of structures under disturbance effects [4-25]. Mahmoud et al. [5] tested the optimal control approach for vibration control of a building. They designed an optimal controller and presented the advantage and effectiveness of the active controller. An aseismic structural control is researched using fundamental control approach by Yamada et al. [6], presented the effect of feedback and feed forward control rules. Li et al. [7] developed a multiplex structures model under wind and earthquake forces and realized open and closed loop control rules for the structure. Meirovitch and Stemple [8] considered the modeling and active control of spread structures. Zhu et al. [9], researched the interaction control for parallel structures to decrease vibrations. Akhiev et al. [10] presented an optimal control of a structure under earthquake forces. Model predictive control with active mass damping using acceleration feedback of structures is investigated by Mei et al. [11]. Djedoui et al. [12] applied an active hybrid closed loop control to decrease the vibrations of the structure under earthquake accelerations. They achieved $15 \%$ reduction in base acceleration and $70 \%$ reduction in displacement and velocity. $\mathrm{Xu}$ et al. [13], proposed active tuned mass dampers for vibration control of building structures under seismic forces. Braz-César et al. [14] used a Magnetorheological (MR) damper to reduce the seismic response of a single degree-of-freedom (SDOF) framed structure by a semi-active fuzzy based control system. They reported the effectiveness of aforementioned system on the reduction of SDOF structure response. Mitchell et al. [15], implemented genetic algorithm based a fuzzy logic controller to reduce the vibration of a highway bridge against various earthquake loads. Design of the linear quadratic regulator (LQR) and the proportional-integral-derivative (PID) controllers for a flexible structural system under earthquake accelerations was investigated by Tinkir et al. [16]. They reported that PID controller was one step ahead of LQR controller according to displacement criteria both in simulation and experiments. Şen et al. [17] presented the bees algorithm based optimization of PID controller for a two-floors structure under seismic excitation. In their study, PID controller performance was developed changing the objective function and the optimization range of the bee algorithm parameters, and very sufficient results were obtained with their proposed active vibration controller. Nevertheless, intelligent and expert based fuzzy logic controllers are considered to be effective tools for control of nonlinear complex systems such as multi-degree of freedom of structural systems with vibration damping problems [18-27]. Additionally, the reported works also show that the genetic algorithm and robust based fuzzy logic controllers have very successful results on the same issue [28-31].

Most of the research reported on this matter focuses on the effectiveness and practicability of new fuzzy concept as interval type- 2 control methodology over vibration control [32-37]. Type-2 fuzzy logic due to containing an inferior membership function and a superior membership function controls uncertainty and imprecision in a best way [38-43], and a type-1 fuzzy set membership function is used to create these two functions. The footprint of uncertainty which is utilized to define a type- 2 fuzzy set is indicated by the interval between these two functions. Fuzzy logic controller is utilized in applications since the inherent uncertainty in the acquiring a satisfactory result is difficult. Therefore, the fuzzy logic controller has become a wellknown technique and some of the reported investigations in literature on the control of non-linear systems consider adaptive or non-adaptive fuzzy control and interval type-2 fuzzy controller [32-43]. Nayak et al. [32] investigated comparative effective analysis of interval type-2 fuzzy-PID controller with and without derivative filter, type-1 fuzzy-PID controller and conventional PID controller for automatic generation control in a two area interconnected thermal power system. They used a novel adaptive symbiotic organism search and optimization techniques to design the proposed controllers and they concluded that symbiotic organism search optimized interval type-2 fuzzy-PID controller outperformed other proposed controllers in terms of less undershoot, overshoot and settling times. Bathaei et al. [33] presented semi-active seismic control of an eleven degree of freedom building model with tuned mass damper (TMD) and adaptive magnetorheological (MR) damper using type1 and -2 fuzzy algorithms. They found that the performance of the proposed type-2 fuzzy controller is more effective than the type-1 fuzzy control for decreasing displacement, acceleration, and base shear of the structure. Trajectory and 
vibration control of a flexible joint manipulator was also investigated by Kelekçi and Kizir [34] using interval type-2 fuzzy logic. In the scope of their study, the proposed controller is designed on the Mamdani based interval type-2 fuzzy logic toolbox using interval triangular membership functions and Karnik-Mendel type reduction algorithm. They reported improved vibration and trajectory tracking behavior of the flexible link with interval type- 2 when compared to the conventional type-1 fuzzy logic controllers. Interval type-2 fuzzy vibration control of an electro-rheological fluid embedded smart structure was investigated by Lin et al. [35] and it was concluded that internal type-2 fuzzy is better than the traditional type-1 fuzzy control in terms of vibration reduction of the smart structure. Also Lin et al. [36] studied vibration control design for a plate structure with actively tunable vibration absorbers using interval type-2 fuzzy system. In their study, solution methods of the fuzzy modeling for design, performance analysis, and optimization of harmonic vibration of thin plates were realized. In the research conducted by Moradi et al. [37] a smart digital phase-locked loop (DPLL) for robust carrier tracking systems was investigated using uncertain rule-based interval type-2 fuzzy (IT2) controllers. They designed IT2 fuzzy controllers to determine optimal DPLL loop filter coefficients resulting in bandwidth to reject noise, handle user dynamics, and sustain locked. After DPLL simulation with Xilinx System Generator, they reported effective responses to various test signals such as phase and frequency steps, frequency ramp and added sinusoidal jitter stimuli with fast acquisition and improved pull in range.

Although interval type-2 fuzzy logic based control approaches have been investigated by many researches as referenced above, a novel design of the IT2NF controller has not been proposed yet for control application on proposed flexible structures using both simulation and experimental methods. Therefore, the motivation of this work is to come up with a novel design of interval type- 2 neuro-fuzzy (IT2NF) controller for active vibration control of two-storey flexible structure against earthquake excitations. Accordingly, two adaptive neural network based fuzzy logic controllers are designed and combined to create an IT2NF controller to reduce the vibrations of flexible building model that occurs during earthquake effect. Additionally, the proposed system is simulated and compared with the experimental results to determine the effectiveness and performance of the proposed controller. Moreover, comparative performance analysis of IT2NF controller is performed based on the simulation and experimental results with respect to cart displacements, deflections, and accelerations of the flexible floors.

\section{Dynamic modeling of the flexible structure}

A flexible structural system model is developed to simulate the dynamic behavior and active vibration control of the building under an earthquake excitation. A system is designed for the control problems raised in structures similar to the nature where the weight constraints result in flexible structures that have to be controlled using feedback techniques. Fig. 1 illustrates the discrete system model and experimental setup including a cart, two floors and a shaker system developed and used in this study. In the given figure, $k_{1}-k_{2}$ and $b_{1}-b_{2}$ are the stiffness and damping coefficients of the first and second floor, respectively. $k_{c}$ and $b_{c}$ are stiffness and damping coefficients of the shaft to which the car is attached. $F_{c}$ is described as control force of the cart. The masses and displacements of the flexible floors are given with $m_{1}, m_{2}, x_{1}$ and $x_{2}$, respectively. The cart assembled on the top floor with gear system acts as an active mass damper (AMD). AMD slides on the bar along horizontal axis. The role of the cart is to decrease the vibrations originated from the shaker motion. The positive directions of horizontal displacement and acceleration $\ddot{X}_{g}$ of the ground motion provided by shake table are towards the right as given in Fig. 1. Two accelerometers are placed on the system to measure the tip deflections of floors of the system.

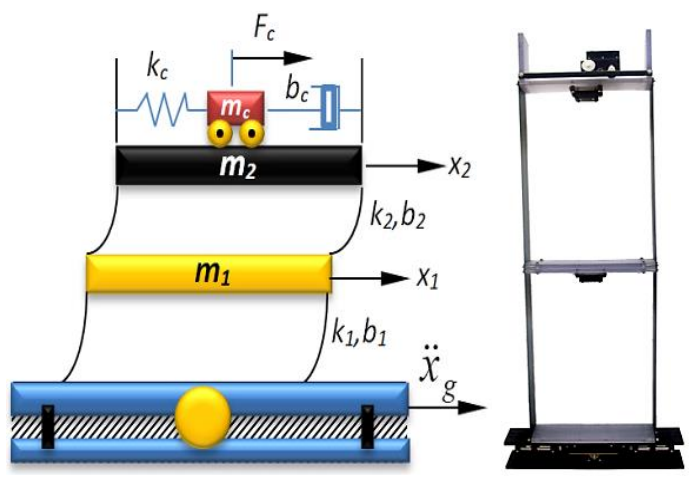

Fig. 1 Discrete system of the model (left) and the experimental setup (right) of the two-storey building

The equation of the motion of the discrete model can be defined as state-space representation given in Eq. (1).

$$
\dot{X}=A X+B U+\ddot{X}_{g} \text { and } Y=C X+D U,
$$

where: $X$ is state variables vector and its transpose is written as follows:

$$
X^{T}=\left[\begin{array}{llllll}
x_{c} & x_{1} & x_{2} & \dot{x}_{c} & \dot{x}_{1} & \dot{x}_{2}
\end{array}\right]
$$

Also $x_{c}$ is the cart linear position relative to the second floor, $x_{1}$ and $x_{2}$ are displacements of the floors. Moreover, output vector $Y$ is presented as follows:

$$
Y^{T}=\left[\begin{array}{lll}
x_{c} & \ddot{x}_{1} & \ddot{x}_{2}
\end{array}\right] \text {. }
$$

In Eq. (4), the driving force of the cart $F_{c}$ is equal to cart's DC motor voltage $V_{m}$ and defined as the input $U$ in Eq. (1).

$$
U=F_{c}=V_{m}
$$

The equation of motion of the discrete system model is also simulated in MATLAB/Simulink for verification of the created model. On the other hand, SolidWorks software is used to draw the flexible structure system, shake table module and cart with geometric configuration and mechanical properties in terms of the experimental setup specifications. Additionally, solid model of the system is imported to MATLAB/SimMechanics software for the development of modeling technique. In MATLAB/ SimMechanics, the flexibility of the floors is defined by considering 
stiffness and damping coefficients and each flexible floor is separated into ten bodies with custom joints which rotate only on $\mathrm{z}$ axis. Joint sensors and joint actuators are added and angle and angular velocity feedbacks are measured using joint sensor blocks. Moreover, these feedbacks are linked with stiffness and damping coefficients. The stiffness and damping forces are used for input of the joint actuator which actuated custom joint during simulations. The stiffness and damping coefficients of the material used in the experimental setup (stainless steel with a dimension of $500 \times 110 \times 1.75 \mathrm{~mm}$ ) are calculated using the values reported in the literature [44-46]. Neves et al. [44] investigated the dynamics of a cantilever beam and a beam free of support conditions. They compared their results with exact solutions and with experimental data from the literature. Comparative study of damping in pristine, steel, and shape memory alloy (SMA) hybrid glass fiber reinforced plastic (GFRP) composite beams of equivalent stiffness was presented by Gupta et al. [45]. In this study, damping ratio was measured experimentally through logarithmic decay method and through experiments damping ratio obtained for SMA hybrid composite beam was found to be higher as compared to the pristine and steel hybrid GFRP composite beams. Also Hunt et al [46], researched that cantilever beam static and dynamic response comparison with mid-point bending for thin medium density fiberboard (MDF) composite panels. As a result of their paper, the damping ratio for the cantilever beam was calculated using the log decrement of the displacement. According to [45], the vertical deflection $w$ of the cantilever beam is written as follow:

$$
w=\frac{P L^{3}}{3 E I} .
$$

The flexural stiffness $K$ is described as:

$$
K=\frac{3 E I}{L^{3}}
$$

where: $P$ is load; $I$ is the moment of inertia; $E$ is the longitudinal Young's modulus; $L$ is the length of beam; $b$ is the width of beam; $t$ is the thickness of beam. For stainless steel $E$ (Young modulus) is $2.10^{11} \mathrm{~Pa}$. For beam with rectangular cross section's moment of inertia is as:

$$
I=\frac{b h^{3}}{12} .
$$

The Eqs. (6) and (7), are calculated as $b=110 \mathrm{~mm}$, $h=1.75 \mathrm{~mm}$ and $L=500 / 10 \mathrm{~mm}$ (therefore, each floor is separated into ten flexible bodies). In addition to these calculations and to verify, finite element (FE) model is constituted in Fig. 2 for stainless steel cantilever beam, and stiffness and damping coefficients are found as $K=260 \mathrm{~N} / \mathrm{mm}$ and $B=0.02 \mathrm{~N} . \mathrm{s} / \mathrm{mm}$.

According to literature and calculations, the properties of the experimental system such as material, stiffness, inertia etc. are assigned to the model in Matlab/ SimMechanics. Fig. 3 shows modeling steps and SimMechanics model.

This modeling approach is provided to obtain the similar model which is convenient to experimental setup of the proposed system. In this modeling, differential equations which are mostly used to find the equation of the motion of the systems are not required anymore and rigid body calculations are converted to flexible body using discrete system model, cantilever beam equations and finite element model. The flexibility of the proposed SimMechanic model is given in Fig. 4.

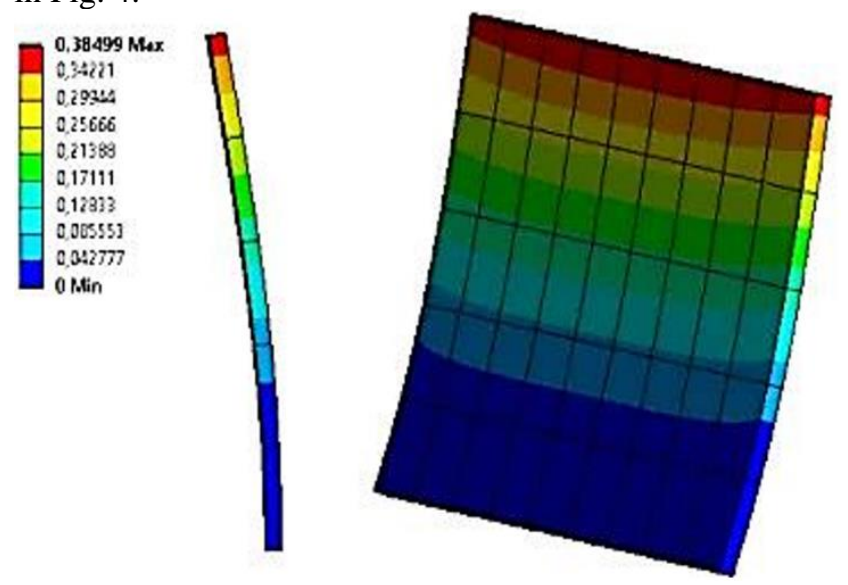

Fig. 2 FE model of the stainless steel cantilever beam

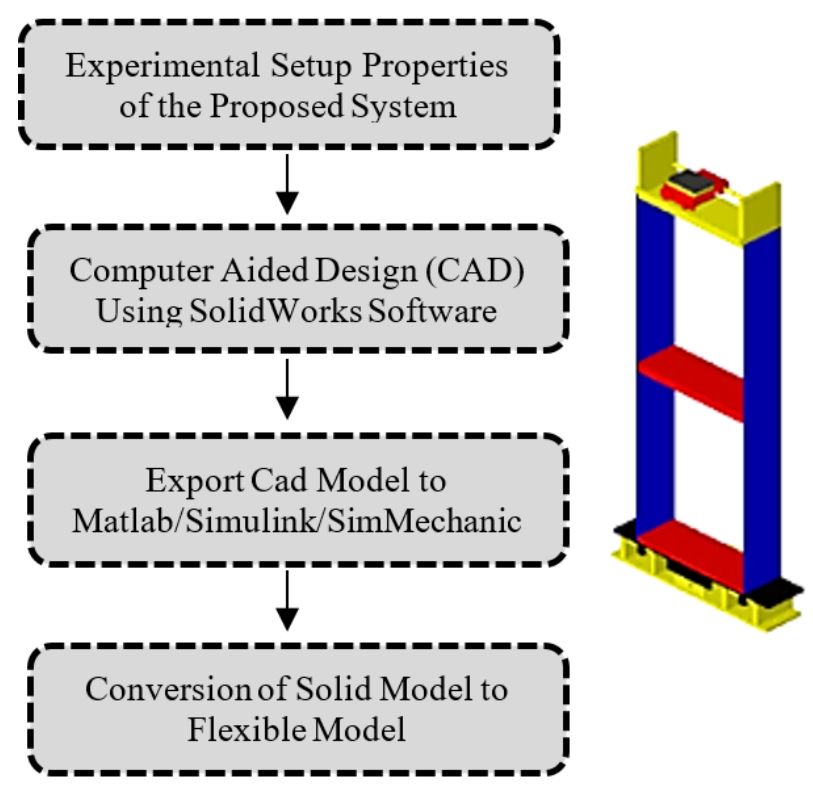

Fig. 3 The modeling steps and SimMechanics solid model

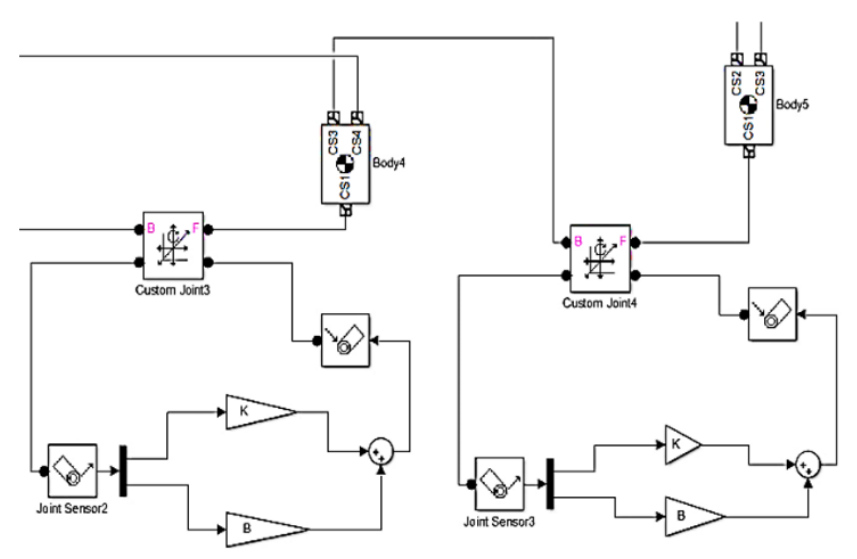

Fig. 4 The flexibility of SimMechanics model

\section{The design of IT2NF controller}

Type-2 fuzzy are utilized to control uncertainty and instability successfully which was defined and proposed by Zadeh [47-48]. Type-2 is characterized with an inferior 
membership function and a superior membership function which can be presented by a type-1 fuzzy membership function [49-52]. Traditionally, type-1 fuzzy logic controllers have been considered widely in control of nonlinear systems. In recent years, it has been found that the type-1 fuzzy logic controllers (FLC) are not sufficient to control uncertainties of the systems [53-58]. The membership function (MF) of a type-2 fuzzy set is three dimensional which includes a footprint of uncertainty. It provides additional degree of freedom that makes it possible to handle the uncertainties as compared to type-1 fuzzy. The reported studies [38-43] show that manually designing and tuning a type-2 FLC gives better response when the number of MF parameters rises.

In this paper, initially, close-loop feedback behavior of flexible structure against scaled Northridge acceleration is simulated to create appropriate artificial neural network base of proposed IT2NF controller for experimental control application. For this purpose, two adaptive neural networks based fuzzy logic controllers are designed with different type of membership functions as gauss, triangular and also these controllers are combined to create an IT2NF controller. The design of two fuzzy logic controllers is realized using artificial neural network based fuzzy inference system. A hybrid learning algorithm is used to identify the parameters of Sugeno-type fuzzy inference systems. A combination of back propagation gradient descent method and least-squares method are applied to train membership function parameters of the fuzzy inference system.

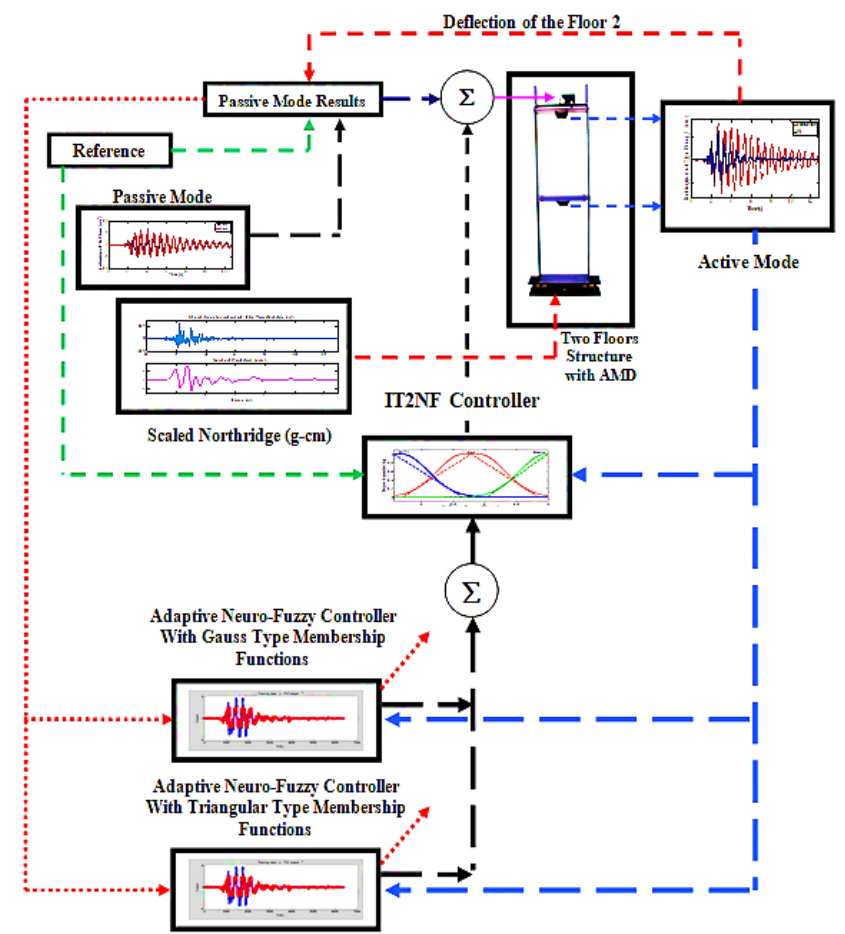

Fig. 5 Block diagram and control methodology of scaled flexible structure

Fig. 5 shows the control methodology and block diagram of a flexible structure controlled by an IT2NF controller under the earthquake excitations.

Many types of membership functions are examined in this study, and three gauss and triangular membership functions are utilized for deflection error of second floor as shown in Fig. 6. The membership functions include negative, zero and positive. The rule bases of each artificial neural network based fuzzy logic controllers (ANNFLC) are composed of 10 rules. Artificial neural network based fuzzy inference system grantees acquiring an optimum range of membership functions. For instance, the rule base of ANNFLC is described as follow; when the deflection error of floor 2 is negative the control voltage becomes $V_{m}$ as [1.952 0.06804]. The ANNFLC architecture consists of five layers with the output of the nodes in each respective layer is represented by $\mathrm{O}_{i}, 1$ where $\mathrm{i}$ is the ith node of layer 1 .

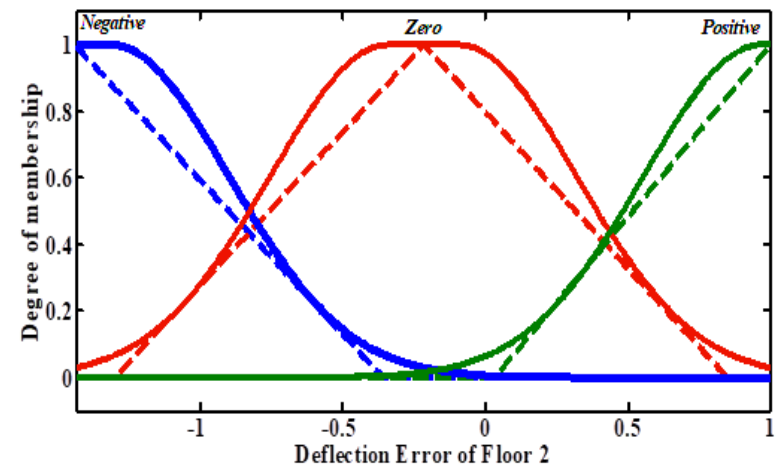

Fig. 6 The membership functions of the proposed IT2NF controller

Layer 1. Generate the membership grades:

$$
\begin{aligned}
& O_{i, l}=\mu_{A_{i}}(x), i=1,2, \\
& O_{i, l}=\mu_{B_{i} 2}(y), i=3,4,
\end{aligned}
$$

where: $x$ (or $y$ ) is the input to the node and $A_{i}\left(\right.$ or $\left.B_{i-2}\right)$ is the fuzzy set associated with this node.

Layer 2. Generate the firing strengths by multiplying the incoming signals and outputs the t-norm operator result, e.g.:

$$
O_{2, i}=w_{i}=\mu_{A i}(x) \times \mu_{B i}(y), i=1,2 .
$$

Layer 3. Normalize the firing strengths:

$$
O_{3, i}=\overline{w_{i}}=\frac{w_{i}}{w_{1}+w_{2}}, i=1,2
$$

Layer 4. Calculate the rule outputs based on the consequent $\left\{p_{i}, q_{i}, r_{i}\right\}$ parameters:

$$
O_{4, i}=\bar{w}_{i} f_{i}=\bar{w}_{i}\left(p_{i} x+q_{i} y+r_{i}\right) .
$$

Layer 5. Computes the overall outputs as the summation of incoming signals:

$$
O_{5, l}=\sum_{i} \bar{w}_{i} f_{i}=\frac{\sum_{i} w_{i} f}{\sum_{i} w_{i}} .
$$

The proposed IT2NF controller includes as follows: 
- 3500 and 500 datum is used for training and checking, respectively.

- 100 epochs are used to train hybrid learning algo-

rithm

The hybrid learning algorithm given above is defined in the literature [49-58]. In the forward pass of the hybrid learning algorithm, node outputs go forward until layer 4 and the consequent are identified by the least-squares method. The adaptive neural network base fuzzy inference system is a fuzzy Sugeno model put in the framework of adaptive systems to facilitate learning and adaptation [3843]. Such framework makes the adaptive neural network base fuzzy inference system control more systematic and less reliant on expert knowledge. To present the adaptive neural network base fuzzy inference system architecture, two fuzzy IF-THEN rules based on a first-order Sugeno model are considered as follows:

Rule 1: If $\left(x\right.$ is $\left.A_{1}\right)$ and $\left(y\right.$ is $\left.B_{1}\right)$ then $\left(f_{1}=p_{1 x}+q_{1 y}+r_{1}\right)$

Rule 2: If $\left(x\right.$ is $\left.A_{2}\right)$ and $\left(y\right.$ is $\left.B_{2}\right)$ then $\left(f_{2}=p_{2 x}+q_{2 y}+r_{2}\right)$

where: $x$ and $y$ are the inputs; $A_{i}$ and $B_{i}$ are the fuzzy sets; $f_{i}$ are the outputs within the fuzzy region specified by the fuzzy rule; $p_{i}, q_{i}$ and $r_{i}$ are the design parameters that are determined during the training process [38-39].

$$
\begin{aligned}
& f=\frac{w_{1}}{w_{1}+w_{2}} f_{1}+\frac{w_{2}}{w_{1}+w_{2}} f_{2}=\bar{w}_{1} f_{1}+\bar{w}_{2} f_{2}=\left(\bar{w}_{1} x\right) p_{1}+ \\
& +\left(\bar{w}_{1} y\right) q_{1}+\left(\bar{w}_{1}\right) r_{1}+\left(\bar{w}_{2} x\right) p_{2}+\left(\bar{w}_{1} y\right) q_{2}+\left(\bar{w}_{1}\right) r_{2} .
\end{aligned}
$$

The adaptive neural network base fuzzy inference system architecture to implement these two rules is shown in Fig. 7, in which a circle indicates a fixed node, whereas a square indicates an adaptive node [38-39].

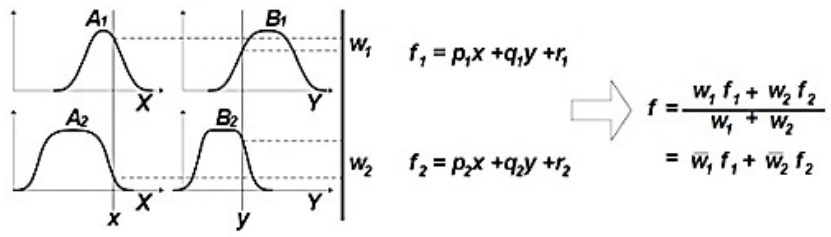

a

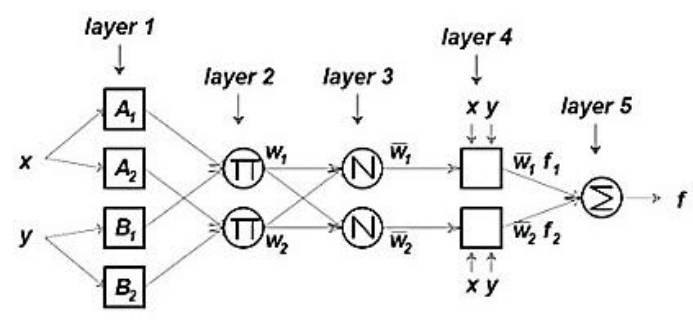

b

Fig. 7 a) Takagi-Sugeno-Kang (TSK) fuzzy inference system with two inputs and two rule; b) Architecture of adaptive neural network base fuzzy inference system of first order TSK model with two inputs

\section{Experimental setup}

Experimental setup of the flexible structural system includes two flexible floors; shake table (The Quanser Shake Table I-40), and a cart [59]. Briefly, floors of the sys- tem are installed on shaker, and disturbance input is performed using shake table same as seismic excitation. Moreover, AMD is a cart that moves in linear direction and installed on the top floor and, it is employed to suppress the structural vibrations and deflections in active mode. The schematic diagram of experimental setup is given in Fig. 8. The geometric configuration of each floor of the system is $0.50 \mathrm{~m}, 0.32 \mathrm{~m}$, and $0.11 \mathrm{~m}$, for the height, length, and depth, respectively. The geometrical parameters of cart are defined as $0.31 \mathrm{~m}, 0.13 \mathrm{~m}$, and $0.11 \mathrm{~m}$, for the height, length, and depth, respectively. The other requirements of the experimental setup are two UMP 1503 power modules, Q8 terminal board cart, PC and MATLAB/Simulink software. The shake table includes a high torque direct drive motor which can drive a $5 \mathrm{~kg}$ mass at $1 \mathrm{~g}$. The maximum travel is \pm 20 $\mathrm{mm}$. Shaker is utilized to form disturbances, simulate earthquakes (up to $10 \mathrm{~Hz}$ ) and check the performance of AMD [59]. The geometric configuration of shaker is $0.508 \mathrm{~m}$ length, $0.152 \mathrm{~m}$ width, $0.089 \mathrm{~m}$ height and $10.8 \mathrm{~kg}$ total mass. Floors of the system are fabricated from two identical single-story modules which assembled on top of each other. Every single-storey moduli consists of two vertical stainless steel beams. The steel beams have a section with $1.75 \mathrm{~mm}$ x $110 \mathrm{~mm}$ dimensions and $0.240 \mathrm{~kg}$ mass.

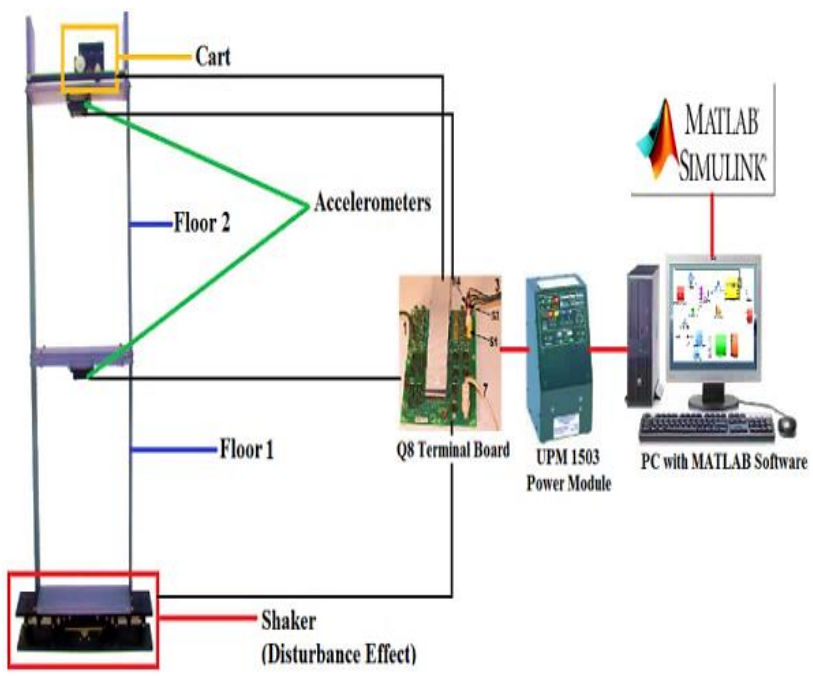

Fig. 8 The experimental setup of the proposed system

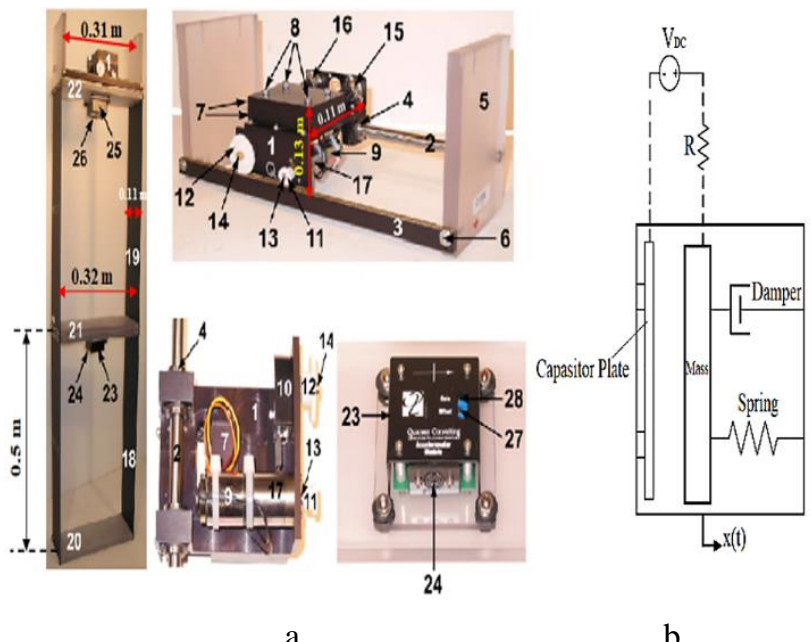

Fig. 9 a) The description of the flexible structure; b) the physical model of the DC accelerometer 
Each floor is equipped with a capacitive DC accelerometer with full-scale range of $\pm 5 \mathrm{~g}$ with signal conditioning. The accelerometers are capable to measure the AC/dynamic acceleration and DC/static acceleration. In order to provide an accurate measurement of the vibration, the accelerometers are mounted in longitudinal directions on the floors of the system. The description of the flexible structure is shown in Fig. 9, a and Table 1. The physical model of the accelerometer is given Fig. 9, b.

Table 1

The description of the flexible structure and cart

\begin{tabular}{|c|c|c|c|}
\hline ID & Description & ID & Description \\
\hline 1 & Cart & 2 & Stainless steel shaft \\
\hline 3 & Track & 4 & Linear bearing \\
\hline 5 & Rack end plate & 6 & Rack set screw \\
\hline 7 & Cart load weight & 8 & Cart load weight set screw \\
\hline 9 & Cart DC motor & 10 & Cart encoder \\
\hline 11 & Cart motor pinion & 12 & Cart position pinion \\
\hline 13 & Cart motor pinion shaft & 14 & Cart position pinion shaft \\
\hline 15 & Cart motor connector & 16 & Cart encoder connector \\
\hline 17 & Cart planetary gearbox & 18 & Floor 1 flexible structure \\
\hline 19 & Floor 2 flexible structure & 20 & Ground floor \\
\hline 21 & Floor 1 & 22 & Floor 2 \\
\hline 23 & Floor 1 accelerometer & 24 & $\begin{array}{c}\text { Floor 1 accelerometer con- } \\
\text { nector }\end{array}$ \\
\hline 25 & $\begin{array}{c}\text { Floor 2 accelerometer } \\
\text { Fing }\end{array}$ & 26 & $\begin{array}{c}\text { Floor 2 accelerometer con- } \\
\text { nector }\end{array}$ \\
\hline 27 & $\begin{array}{c}\text { Accelerometer offset po- } \\
\text { tentiometer }\end{array}$ & 28 & $\begin{array}{c}\text { Accelerometer gain potenti- } \\
\text { ometer }\end{array}$ \\
\hline
\end{tabular}

\section{Results and discussion}

The Northridge earthquake happened on January 17, 1994, at 04:31 Pacific standard time in Reseda, in Los Angeles, California. The acceleration of ground was measured $1.7 \mathrm{~g}\left(16.7 \mathrm{~m} / \mathrm{s}^{2}\right)$ which was one of the highest earthquakes recorded in an urban in North America. The Northridge earthquake had a maximum displacement of $16.92 \mathrm{~cm}$ which is scaled down to $1.5 \mathrm{~cm}$ (set as $x_{\text {max }}$ ) in this study.

In order to obtain the same acceleration as Northridge, the time period is shortened from 39.98 to 11.91 seconds as suggested in [60]. Fig. 10 displays the recorded earthquake acceleration in gravitational units and the scaled position set point (in centimeters) for the Northridge earthquake. Captured simulations and flexibility of the floors obtained from MATLAB/SimMechanics model are given in Fig. 11.

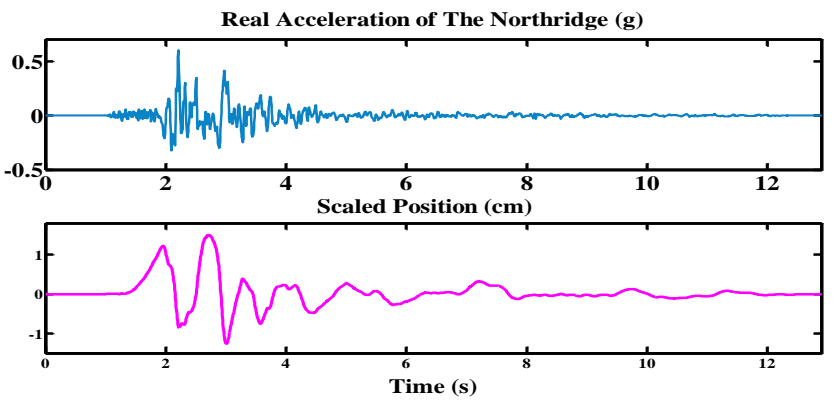

Fig. 10 Real acceleration and scaled position of the Northridge earthquake

The deflection results of the floors in passive mode simulations are shown in Fig. 12. As seen in Fig. 12, maximum deflections of first and second floor in passive mode are acquired as $1.9 \mathrm{~cm}$ and $3.1 \mathrm{~cm}$, respectively. The second floor deflection is more than the first-floor response because deflection is increased by bending moment via height of the structure. Also maximum deflections of the floors occur between 2 and 4 seconds under the Northridge Earthquake. After 4 seconds the deflections decreased step by step.

The deflection results of IT2NF controlled simulation model are given in Figs. 13-14. From these simulation results the following; the values of total deflection of the floors are lower than passive mode deflection responses and maximum floor deflections are evaluated for IT2NF controlled system as floor 1 is $1.1 \mathrm{~cm}$ and floor 2 is $1.8 \mathrm{~cm}$. Fig. 15 shows the displacement of IT2NF controlled cart in simulations. Maximum displacement of cart is obtained as $5.6 \mathrm{~cm}$.

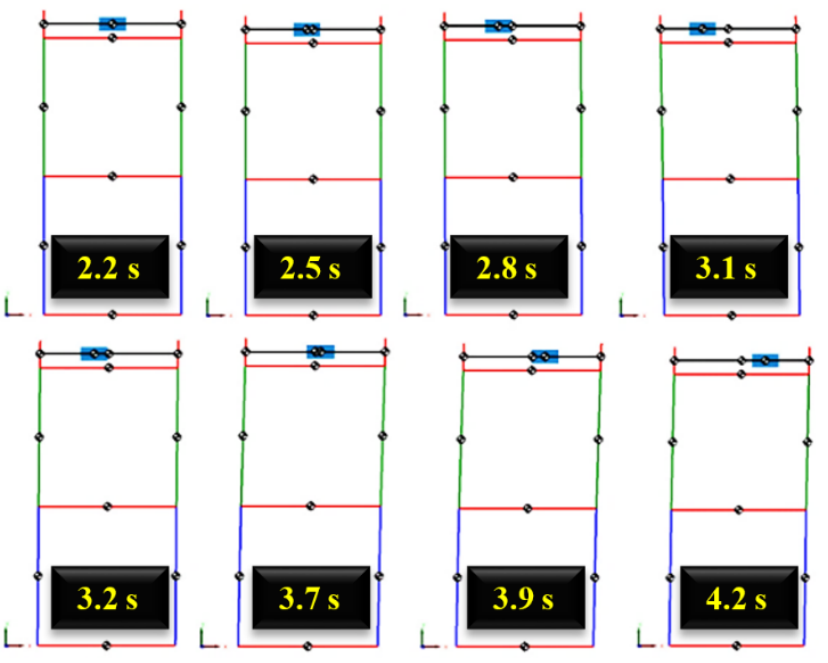

Fig. 11 Animations of simulation model against to Northridge Earthquake in passive mode

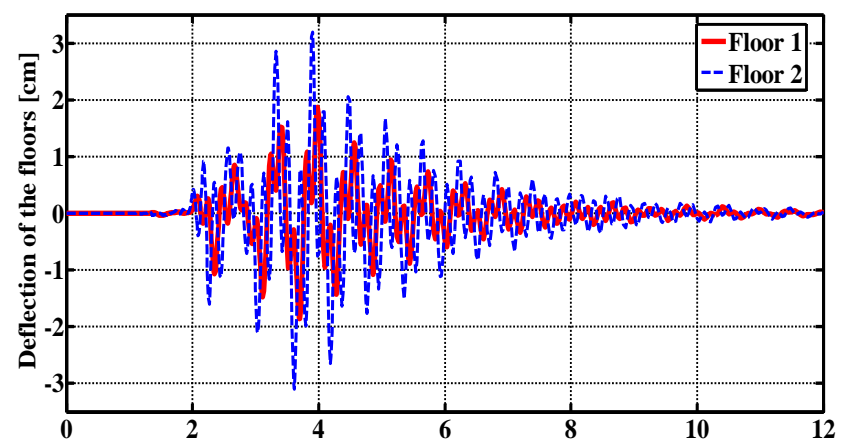

Fig. 12 Passive mode deflection results in simulations

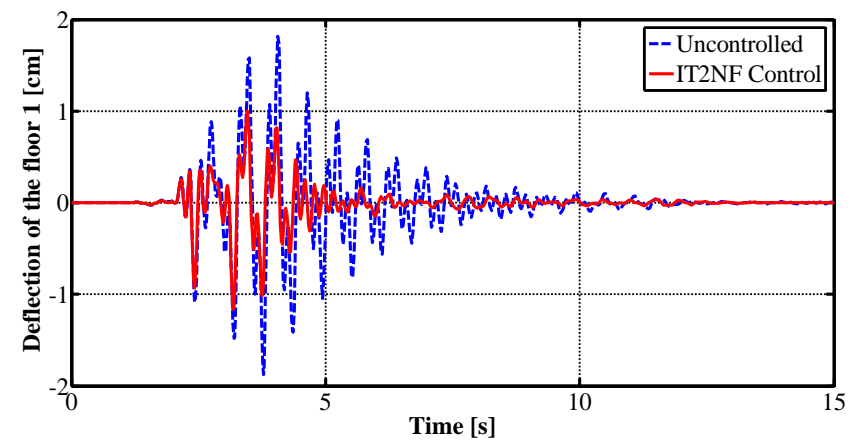

Fig. 13 The deflection comparison of uncontrolled and IT2NF controlled system for floor 1 in simulations 


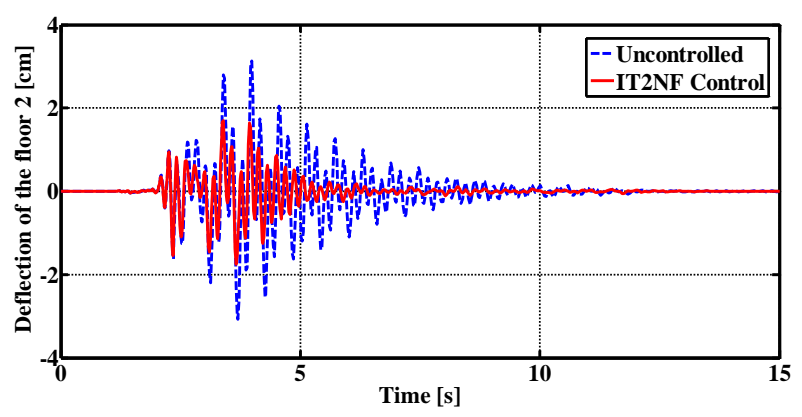

Fig. 14 The simulations showing the deflections of uncontrolled and IT2NF controlled system for floor 2

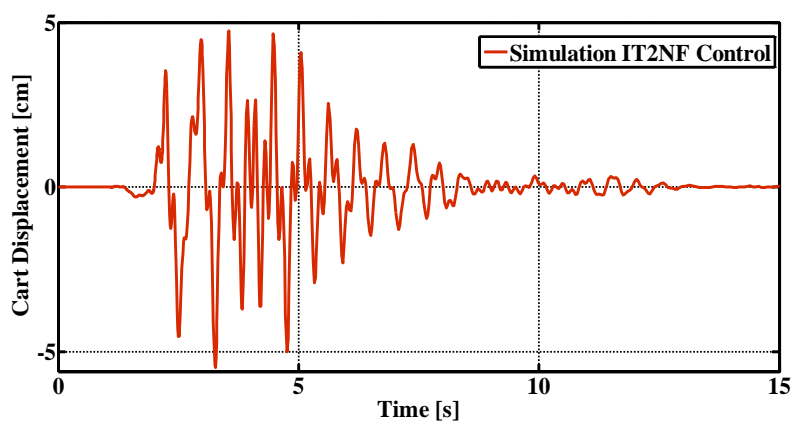

Fig. 15 IT2NF controlled cart displacement in simulations

In active mode, experimental results of IT2NF controlled system are given in Figs. 16 and 17. As seen, maximum deflections of the first and second floor in passive mode are acquired as 2.1 and $3.3 \mathrm{~cm}$, respectively. From these experimental results, maximum floor deflections are evaluated for IT2NF controlled system as 1.8 and $2.4 \mathrm{~cm}$ for the first and second floor, respectively. The experimental acceleration results of passive mode and IT2NF controlled the floors are given in Figs. 18 and 19. As seen in Fig. 18, first and second floor maximum acceleration in passive mode are obtained as 6.5 and $7.1 \mathrm{~m} / \mathrm{s}^{2}$, respectively. In active mode, experimental acceleration results of IT2NF controlled system given in Fig. 19 are obtained for first and second floors as 5.2 and $7.8 \mathrm{~m} / \mathrm{s}^{2}$, respectively. When the passive and active mode acceleration results are compared, it is possible to say that an acceleration response in passive mode continues as oscillations affecting the deflection responses of the floors in the same mode. The displacement and voltage of IT2NF controlled cart in experiment are given in Figs. 20-21.

Maximum cart displacement is obtained as $6.15 \mathrm{~cm}$. and IT2NF controlled cart voltage is found as $2.7 \mathrm{~V}$.

According to given figures based simulation and experimental results; the following discussions are derived as:

- The experimental results verified that novel design IT2NF controller decreased the total deflections of first and second floors by $72.3 \%$ and $68.7 \%$, respectively in comparison to uncontrolled responses.

- The experimental results proved that novel design IT2NF controller reduced floor 1 total accelerations by $64.8 \%$ and floor 2 total accelerations by $54.6 \%$ in comparison to uncontrolled results.

- It is concluded that novel design IT2NF controller is very successful in terms of active vibration control of the flexible structure under disturbance effect such as earth- quake excitation. Also the numerical comparison of simulation and experimental results is given in Table 2.

Table 2

The comparison of the results

\begin{tabular}{|c|c|c|c|c|}
\hline Approaches & \multicolumn{2}{|c|}{ Simulation } & \multicolumn{2}{c|}{ Experimental } \\
\hline $\begin{array}{c}\text { Maximum deflection re- } \\
\text { sults }\end{array}$ & $\begin{array}{c}\text { Floor-1, } \\
\mathrm{cm}\end{array}$ & $\begin{array}{c}\text { Floor-2, } \\
\mathrm{cm}\end{array}$ & $\begin{array}{c}\text { Floor-1, } \\
\mathrm{cm}\end{array}$ & $\begin{array}{c}\text { Floor-2, } \\
\mathrm{cm}\end{array}$ \\
\hline Passive (Uncontrolled) & 1.9 & 3.1 & 2.1 & 3.3 \\
\hline IT2NF Controlled & 1.1 & 1.8 & 1.8 & 2.4 \\
\hline
\end{tabular}

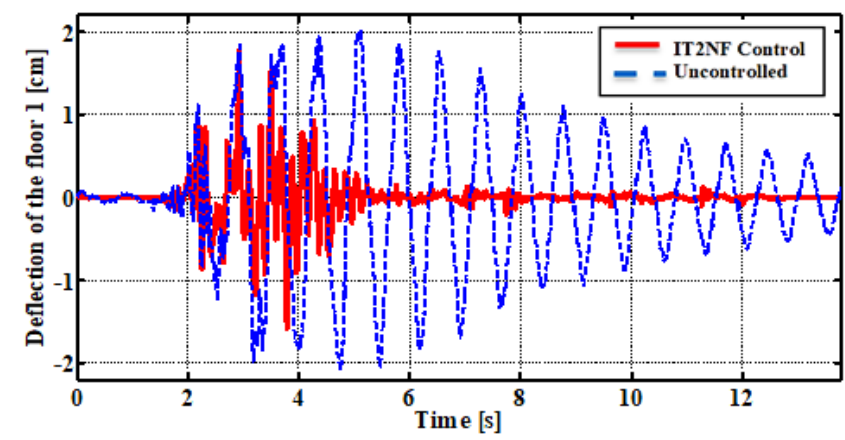

Fig. 16 The deflection comparison of uncontrolled and IT2NF controlled system for floor 1 in experiments

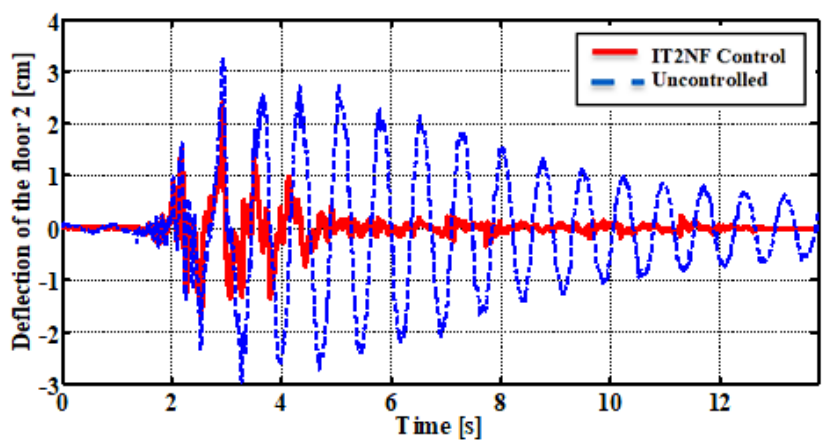

Fig. 17 The deflection comparison of uncontrolled and IT2NF controlled system for floor 2 in experiments

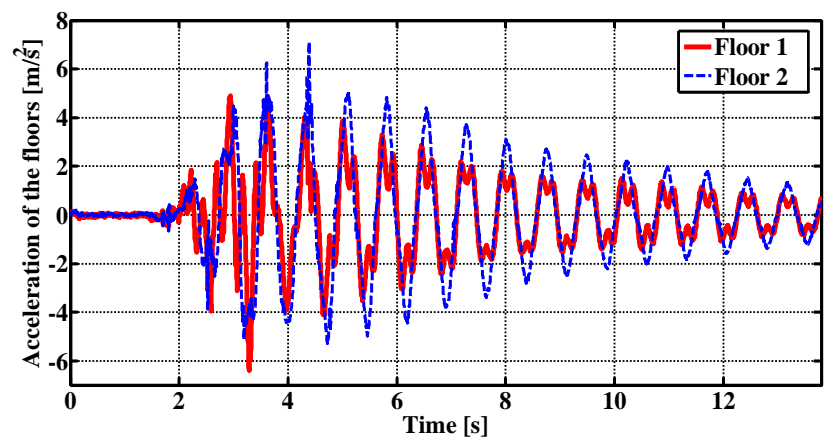

Fig. 18 Passive mode experimental acceleration results

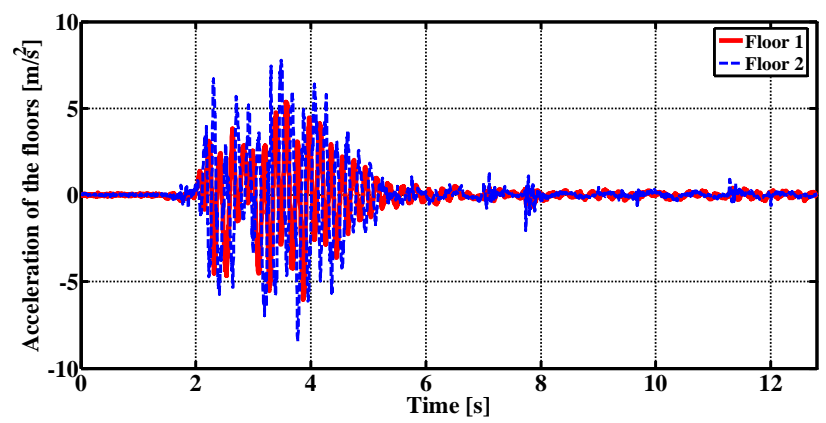

Fig. 19 IT2NF controlled mode experimental acceleration results 


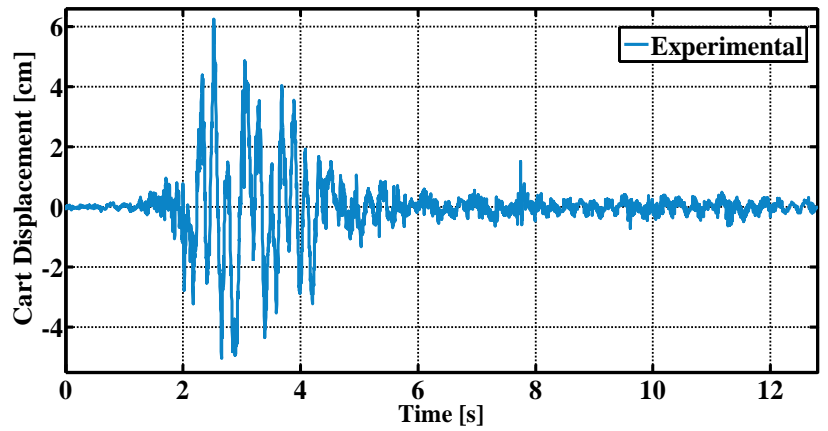

Fig. 20 IT2NF controlled cart displacement in experiments

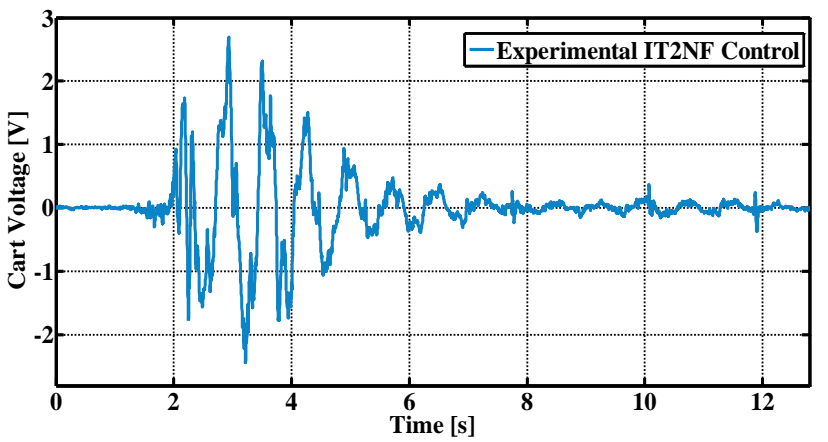

Fig. 21 The change of cart voltage in active mode

\section{Conclusions}

The active control methods for the disturbances are shown to be more effective than the passive controllers in terms of decreasing the vibration of structures under disturbance effects. In this study, a novel design of interval type-2 neuro-fuzzy (IT2NF) controller is proposed for active vibration control of a flexible structure during an earthquake. A combination of the dynamic model and simulations are carried out to determine the performance of the proposed controller, accordingly experimental setup is established to verify the accuracy of the simulated models. The experimental results reveal a respectable reduction both in the total deflections and the accelerations of the floors under the scaled Northridge Earthquake accelerations. The active controller is proposed and designed in this study can be seen as an alternative an active vibration controller for multi-degree of freedom of flexible systems under the disturbances such as earthquake excitations.

\section{Acknowledgments}

This work is supported by Selçuk University (Project No: 09401048) and Necmettin Erbakan University (Project No: 121619007).

\section{References}

1. AlMusbahi, S; Güngör, A. 2019. A composite building isolation system for earthquake protection, Engineering Science and Technology, an International Journal 22(2): 399-404.

2. Ghaffarzadeh, H; Dehrod, E. A; Talebian, N. 2012. Semi-active fuzzy control for seismic response reduction of building frames using variable orifice dampers subjected to near-fault earthquakes, Journal of Vibration and Control 19(13): 1980-1998.
3. Talib, E; Shin, J. H; Kwak, M. K. 2019. Designing multi-input multi-output modal-space negative acceleration feedback control for vibration suppression of structures using active mass dampers, Journal of Sound and Vibration 439: 77-98.

4. Xu, Y. L.; He, Q; Ko, J. M. 1999. Dynamic response of damper-connected adjacent buildings under earthquake excitation, Engineering Structures 21(2): 135148.

5. Mahmoud, M. S; Zribi, M; Soh, Y. C. 2000. Optimal control of seismically-excited building structures, Computers and Structures 74(5): 521-533.

6. Yamada, K; Kobori, T. 2001. Fundamental dynamics and control strategies for aseismic structural control, Int. J. of Solids and Structures 38(34-35): 6079-6121.

7. Li, Q. S; Fang, J. Q; Jeary, A. P; Liu, D. K. 2001. Decoupling control law for structural control implementation, Int. J. of Solids and Structures 38(34-35): 61476162.

8. Meirovitch, L; Stemple, T. J. 2001. A new approach to the modelling of distributed structures for control, Journal of the Franklin Institute 338: 241-254.

9. Zhu, H; Wen, Y; Lemura, H. 2001. A study on interaction control for seismic response of parallel structures, Computers and Structures 79: 231-242.

10. Akhiev, S. S; Aldemir, U; Bakioğlu, M. 2002. Multipoint instantaneous optimal control of structures; Computers and Structures 80(11): 909-917.

11. Mei, G; Kareem, A; Kantor, J. C. 2002. Model Predictive Control of structures under Earthquakes using Acceleration Feedback, J. of Engineering Mechanics 128(5): 574-585.

12. Djedoui, N; Ounis, A; Abdeddaim, M. 2016. Active vibration control for base-isolated structures using a PID controller against earthquakes, In International Journal of Engineering Research in Africa, Trans. Tech. Publications 26: 99-110.

13. Xu, L; Yunyan, Y; Yanliang, C. 2018. Active vibration control for seismic excited building structures under actuator saturation, measurement stochastic noise and quantization, Eng. Struct. 156: 1-11.

14. Braz-César, M; Barros, R. 2018. Semi-active fuzzy based control system for vibration reduction of a sdof structure under seismic excitation, Smart Struct. Syst. 21(4): 389-95.

15. Mitchell, R; Cha, Y. J; Kim, Y; Mahajan, A. A. 2015. Active control of highway bridges subject to a variety of earthquake loads, Earthquake Eng. Vib. 14(2): 253-263.

16. Tınkır, M; Kalyoncu, M; Şahin, Y. 2015. Modelling and controller design for a flexible structure system against disturbance effects, low frequency noise, Vibration and Active Control 34(4): 525-548.

17. Şen, A; Tınkır, M; Kalyoncu, M. 2018. Optimisation of a PID controller for a two-floors structure under earthquake excitation based on the bees algorithm, Journal of Low Frequency Noise, Vibration and Active Control 37(1): 107-127.

18. Rahman, T. A. Z; As'arry, A.; Abdul Jalil, N. A.; Kamil, R. 2019. Dynamic modelling of a flexible beam structure using feedforward neural networks for active vibration control, International Journal of Automotive and Mechanical Engineering 16(1): 6263-6280.

19. Kolekar, S; Venkatesh, K; Oh, J. S; Choi, S. B. 2019. Vibration controllability of sandwich structures with 
smart materials of electrorheological fluids and magnetorheological materials: a review, Journal of Vibration Engineering \& Technologies 7: 359-377.

20. Güçlü, R; Yazıcı, H. 2007. Fuzzy logic control of a nonlinear structural system against earthquake induced vibration, Journal of Vibration and Control 13(11): 15351551.

21. Güçlü, R; Yazıcı, H. 2008. Vibration control of a structure with ATMD against earthquake using fuzzy logic controllers, Journal of Sound and Vibration 318(1-2): 36-49.

22. Park, K. S; Ok, S. Y. 2012. Optimal design of actively controlled adjacent structures for balancing the mutually conflicting objectives in design preference aspects, Engineering Structures 45: 213-222.

23. Casciati, F.; Rodellar, J; Yıldırım, U. 2012. Active and semi-active control of structures - theory and applications: a review of recent advances, Journal of Intelligent Material Systems and Structures 23(11): 11811195.

24. Wang, Q; Wang, J; Ma, K. 2019. Research on semiactive control method of a building structure based on non-smooth control, Earthquake Engineering and Engineering Vibration 18(2): 425-432.

25. Park, W; Park, K. S. 2019. Optimal design of hybrid control system for the wind and earthquake excited buildings, KSCE Journal of Civil Engineering 23(2): 744-753.

26. Karami, K; Manie, S; Ghafouri, K; Nagarajaiah, S. 2019. Nonlinear structural control using integrated DDA/ISMP and semi-active tuned mass damper, Engineering Structures 181: 589-604.

27. Mirfakhraei, S. F; Andalib, G; Chan, R. 2019. Numerical investigation on toggled actuator forces in active vibration control system, Advance Researches in Civil Engineering 1(2): 16-35.

28. Nguyen, S. D; Jung, D; Choi, S. B. 2017. A robust vibration control of a magnetorheological damper based railway suspension using a novel adaptive type 2 fuzzy sliding mode controller, Shock and Vibration, Article ID 7306109, 14 pages.

29. Yordanova, S; Gueorguiev, B; Slavov, M. 2020. Design and industrial implementation of fuzzy logic control of level in soda production, Engineering Science and Technology, an International Journal 23: 691-699.

30. Civelek, Z. 2020. Optimization of fuzzy logic (TakagiSugeno) blade pitch angle controller in wind turbines by genetic algorithm, Engineering Science and Technology, an International Journal 23(1): 1-9.

31. Ali, A. A.; Lateef, R. A. R.; Saeed, M. W. 2017. Intelligent tuning of vibration mitigation process for single link manipulator using fuzzy logic, Engineering Science and Technology, an International Journal 20: 12331241.

32. Nayak, J. R; Shaw, B; Sahu, B. K. 2018. Application of adaptive-SOS (ASOS) algorithm based interval type2 fuzzy-PID controller with derivative filter for automatic generation control of an interconnected power system, Engineering Science and Technology, an International Journal 21(3): 465-485.

33. Bathaei, A; Zahrai, S. M; Ramezani, M. 2017. Semiactive seismic control of an 11-DOF building model with TMD+MR damper using type- 1 and -2 fuzzy algorithms, Journal of Vibration and Control 24(13): 29382953.

34. Kelekci, E; Kizir, S. 2019. Trajectory and vibration control of a flexible joint manipulator using interval type-2 fuzzy logic, ISA Transactions 94: 218-233.

35. Lin, C. J; Lee, C. Y; Liu, Y; Cheng, C. H. 2014. Interval type-2 fuzzy vibration control of an ERF embedded smart structure, International Journal of Mechanical, Aerospace, Industrial and Mechatronics Engineering 8(7): 1211-1217.

36. Lin, C. J; Lee, C. Y; Liu, Y. 2017. Vibration control design for a plate structure with electrorheological atva using interval type-2 fuzzy system, Applied Science 7(7): 1-27.

37. Moradi, M; Ehsanian, M. 2020. A smart DPLL for robust carrier tracking systems using uncertain rule-based IT2 fuzzy controllers, Engineering Science and Technology, an International Journal 23(4): 821-830.

38. Güler, İ; Übeyli, E. D. 2005. Automatic detection of ophthalmic artery stenosis using the adaptive neurofuzzy inference system, Engineering Applications of Artificial Intelligence 18(4): 413-422.

39. Mendel, J. M. 2017. Uncertain Rule-Based Fuzzy Logic Systems, Introduction and New Directios, Springer International Publishing AG, 684 pages.

40. Mamdani, E. 1994. Fuzzycontrol - a misconception of theory and application, IEEE Expert 9(4): 27-28.

41. Hagra, H. 2004. A Hierarchical type-2 fuzzy logic control architecture for autonomous mobile robots, IEEE Trans. Fuzzy Syst. 12(4): 524-539.

42. Adak, A. K; Bhowmik, M. 2011. Interval cut-set of interval-valued intuitionistic fuzzy sets, Afr. J. Maths. Comput. Sci. Res. 4(4): 192-200.

43. Liang, Q; Mendel, J. M. 2000. Interval type-2 fuzzy logic systems: Theory and design; IEEE Trans. Fuzzy Syst. 8: 535-550.

44. Neves, A. C; Simões, F. M. F; Pinto da Costa, A. 2016. vibrations of cracked beams: discrete mass and stiffness models, Computers and Structures 168: 68-77.

45. Gupta, A. K; Velmurugan, R; Joshi, M. 2018. Comparative study of damping in pristine, steel, and shape memory alloy hybrid glass fiber reinforced plastic composite beams of equivalent stiffness, Defence Science Journal 68(1): 91-97.

46. Hunt, J. F; Zhang, H; Guo, Z; Fu, F. 2013. Cantilever beam static and dynamic response comparison with midpoint bending for thin MDF composite panels, BioResources 8(1): 115-129.

47. Zadeh, L. A. 1988. Fuzzy logic, Computer 1(4): 83-93.

48. Zadeh, L. A. 1988. Knowledge representation in fuzzy logic, IEEE Trans. Knowl. Data Eng. 1: 89-100.

49. Jang, J. S. R. 2003. ANFIS: adaptive-network-based fuzzy inference system, IEEE Trans. on Systems, Man and Cybernetics 23(3): 665-685.

50. Lei, Z; Qixin, C; Jay, L. 2004. A hybrid one-by-one learning with incremental learning algorithm in CMAC, Proceedings of the SmWorld Congress on Intelligent Control and Automation, Hangzhou. P.R. China, June 15-19.

51. Daohang, S; Vladimir, B. B. 2002. An on-line hybrid learning algorithm for multilayer perceptron in identification problems, Computers and Electrical Engineering 28: 587-598. 
52. Denai, M. A; Pallis, F; Zeghbib, A. 2004. ANFIS based modeling and control of nonlinear systems: A tutorial, IEEE International Conference on Systems, Man and Cybernetics, 10-13 Oct, pp. 3433-3438.

53. Siddique, N; Tokhi, M. O. 2006. GA-based neural fuzzy control of flexible-link manipulators, Engineering Letters 13(2):148-157.

54. Rezaeian, A; Yousefi-Koma, A; Shasti, B; Doosthoseini, A. 2008. ANFIS modeling and feed forward control of shape memory alloy actuators, International Journal of Mathematical Models and Methods in Applied Sciences 2(2): 228-235.

55. Chopra, S; Mitra, R; Kumar, V. 2007. A Neuro fuzzy learning and its application to control system, International Journal of Computational Intelligence 3(1): 72-78.

56. Bodyanskiy, Y; Pliss, I; Vynokurova, O. 2008. Adaptive wavelet-neuro-fuzzy network in the forecastıng and emulation tasks, International Journal "Information Theories \& Applications 15: 47-55.

57. Kalaichelvi, V; Sivakumar, D; Karthikeyan, R; Palanikumar, K. 2009. Prediction of the flow stress of $6061 \mathrm{Al}-15 \% \mathrm{SiC}-\mathrm{MMC}$ composites using adaptive network based fuzzy inference system, Materials and Design 30(4): 1362-1370.

58. Denai, M. A;Palis, F; Zeghbib, A. 2007. Modeling and control of non-linear systems using soft computing techniques, Applied Soft Computing 7(3): 728-738.

59. Quanser Innovative Educate Company. 2019. Shake Table I-40 and Active Mass Damper Producheet, https://www.quanser.com/products/active-massdamper.

60. Kraus, I; Cerovecki, A. 2018. Comparison of free-field and foundation input motions from experimentally tested built environments, Geotechnical Codes and Design Methods 2(2-3): 895-900.
M. Tınkır, M. Kalyoncu, H. Ç. Sezgen

\section{A NOVEL DESIGN OF INTERVAL TYPE-2 NEURO- FUZZY CONTROLLER FOR FLEXIBLE STRUCTURE}

\section{S u m m a r y}

The aim of this research is to develop a novel design of interval type-2 neuro-fuzzy (IT2NF) controller for active vibration control of a flexible structure during an earthquake. For this purpose, two adaptive neural network based fuzzy logic controllers are designed and combined to create the novel design of an IT2NF controller to reduce the vibrations of two-storey flexible building model that occur during earthquake disturbance effects. Accordingly, dynamic modeling of a flexible structure is realized and simulated using the MATLAB / SimMechanics. Then, an experimental setup consisting of two-storey flexible structure, active mass damper (AMD) and shaker is established. Additionally, IT2NF controller is implemented in simulation and experimental models, and the effectiveness and performance of the IT2NF controller are tested under the scaled Northridge Earthquake acceleration. The obtained simulations and experimental responses are evaluated in terms of cart displacements, deflections, and accelerations of the flexible floors showing a good agreement between the simulations and the experimental results. The results show that the designed novel IT2NF controller reduced the total deflections of first and second floor by $72.3 \%$ and $68.7 \%$, respectively, when compared with the uncontrolled system. Additionally, it is also found that the designed IT2NF controller is able to reduce the accelerations of the first and second floor by $64.8 \%$ and $54.6 \%$, respectively. The proposed and designed control method reported in this study can be employed as an active vibration controller for multi-degree of freedom of flexible systems under the disturbances such as earthquake excitations.

Keywords: interval type- 2 neuro-fuzzy control, flexible structure, active vibration control, modeling and simulation, experimental.

Received January 21, 2020

Accepted August 07, 2021

This article is an Open Access article distributed under the terms and conditions of the Creative Commons Attribution 4.0 (CC BY 4.0) License (http://creativecommons.org/licenses/by/4.0/). 